УДК: 621.3

НЕЙЧЕВ О. В., кандидат технічних наук, доцент

(Український державний університет залізничного транспорту),

САДОВИЙ К. В., кандидат технічних наук, доцент

(Харківський національний університет Повітряних Сил),

СОСУНОВ О. О., кандидат технічних наук, доцент

(Український державний університет залізничного транспорту),

ХІСМАТУЛІН В. Ш., кандидат технічних наук, професор

(Український державний університет залізничного транспорту)

\title{
Синтез оптимальної за швидкодісю системи керування стрілочним електроприводом
}

У статті запропоновано синтез системи керування стрілочним електродвигуном з нульовою швидкістю в кінці переводу, оптимальної за критерієм максимальної швидкодіі. Подано математичне формулювання мети керування, критерію оптимальності й обмеження на керуючий вплив. Розроблено математичну модель привода з двигуном постійного струму. Проведено аналіз керованості об'єкта і нормальності варіаційної задачі. Синтез оптимальної системи керування виконано з використанням принципу максимуму Л. С. Понтрягіна.

Ключові слова: стрілочний електропривод, вістряк, рамна рейка, оптимальна за швидкодією система керування, принции максимуму.

\section{Вступ}

Алгоритм роботи стрілочного привода складається 3 виконання декількох операцій. Після вмикання електродвигуна його вал починає вільне обертання (холостий хід). Одночасно готується коло реверсування. Наступний етап - механічне відмикання стрілки. Заключний етап - замикання стрілки, отримання сигналу контролю крайнього положення i тільки після цього вимикання двигуна [1].

У момент завершення робочого ходу шибера його лінійна швидкість має максимальне значення, і процес гальмування інерційної системи супроводжується тільки силовим фактором [2]. Робота 3 поглинання кінетичної енергії в кінці переводу стрілки в цей момент здійснюється лише за рахунок сил тертя в кінематичних парах вістряк - повзуни, пружних сил рамної рейки і гарнітури і лише частково поглинається фрикційною муфтою. На практиці це призводить до ударів вістряка по рамній рейці, що послаблює кріплення деталей і вузлів електропривода і гарнітури, сприяє передчасному зносу механізмів i може призвести до виникнення позаштатної ситуації [2].

\begin{tabular}{l}
\hline Аналіз останніх досліджень і публікацій \\
\hline У роботі [3] зазначено, що фактичний середній \\
термін служби елементів стрілочних переводів для \\
частини проектів значно нижче нормативного терміну \\
служби, який повинен забезпечуватися поряд 3
\end{tabular}

технологією виробництва та належною експлуатацією також i відповідною конструкцією переводу. Відзначається, що вихід з ладу стрілочних переводів обумовлений в основному технологічними й експлуатаційними факторами. Однак близько $23 \%$ несправностей обумовлено конструктивними факторами.

Одним зі шляхів збільшення середнього терміну служби елементів стрілочного переводу і підвищення безпеки руху поїздів [4] є зменшення впливу вістряка на рамну рейку в кінці переводу стрілки. 3 цією метою слід гасити кінетичну енергію рухомих мас в кінці переводу стрілки шляхом зменшення швидкості в момент завершення переводу до нуля або до досить малої величини.

Вимога нульової швидкості в момент завершення переводу стрілки суперечить вимозі мінімального часу переводу стрілки. Вирішення цієї суперечності може бути досягнуто при використанні алгоритму керування, оптимального за швидкодією 3 нульовою швидкістю в момент закінчення керування.

Метою статті $\epsilon$ синтез алгоритму керування стрілочним електродвигуном, оптимального за критерієм максимальної швидкодії 3 нульовою швидкістю в момент закінчення керування.

() О. В. Нейчев, К. В. Садовий, О. О. Сосунов, В. Ш. Хісматулін, 2019 


\section{Основна частина}

Математична формалізація задачі. Розв'язати задачу синтезу алгоритму керування стрілочним електродвигуном пропонується за допомогою теорії оптимального керування [5, 6]. Як відомо, для постановки задачі синтезу оптимального керування необхідно мати такі вихідні дані [5-8]:

1) інформацію про об'єкт керування;

2) інформацію про зовнішні дії;

3) інформацію про мету керування;

4) інформацію про показник якості та критерії оптимальності керування;

5) інформацію про обмеження, що накладаються на величини вхідних впливів і на координати стану об'єкта.

На основі зазначених вихідних даних необхідно знайти закон керування, який реалізує поставлену мету керування при накладених обмеженнях і забезпечить екстремальне значення заданого показника якості.

Як об'єкт керування розглядається стрілочний електропривод 3 двигуном постійного струму. 3 урахуванням того, що інерційність кола живлення якоря значно менше інерційності рухомих механічних частин, динаміка роботи привода визначається рівняннями $[1,9]$

$\varphi^{\prime}(t)=k_{p} \cdot \Omega(t)$

$\Omega^{\prime}(t)=-\frac{1}{T} \Omega(t)+\frac{k_{d}}{T} u(t)$,

де $\varphi(t)$ - кут повороту головного вала;

$k_{p}$ - коефіцієнт передачі редуктора;

$\Omega(t)$ - кутова швидкість обертання якоря;

$T$ - електромеханічна стала двигуна;

$k_{d}$ - коефіцієнт підсилення двигуна за швидкістю;

$u(t)$ - напруга живлення постійного струму.

Початкові і граничні умови для координат стану $\varphi(t)$ та $\Omega(t)$ :

- початковий стан $\left(t_{0}=0\right)$

$\varphi(0)=0, \quad \Omega(0)=0 ;$

- кінцевий стан $\left(t=t_{k}\right)$

$\varphi\left(t_{k}\right)=\varphi_{k}, \quad \Omega\left(t_{k}\right)=0$

Обмеження: напруга живлення $u(t)$ не повинна перевищувати припустиме значення $U_{m}$ :

$\left|u(t) \leq U_{m}\right|$

Показник якості $J$ - інтервал часу переводу, критерій оптимальності - мінімум інтервалу часу переводу:
$J=\int_{t_{0}}^{t_{k}} L(\varphi, \Omega, u, t) d t=t_{k}-t_{0} \rightarrow \min$,

де $t_{k}$ - нефіксований момент закінчення керування;

$L(\varphi, \Omega, u, t)=1 \quad$ - підінтегральна функція (Лагранжіан) показника якості (2).

Розв'язання задачі синтезу. Для зручності розв'язання задачі синтезу доцільно перетворити змінні стану таким чином, щоб отримати задачу 3 нульовим кінцевим станом. Для цього зробимо заміну змінних:

$z_{1}(t)=\varphi_{k}-\varphi(t)$

$z_{2}(t)=-\varphi^{\prime}(t)=-k_{p} \Omega(t)$.

При такій заміні рівняння (1) набуває вигляду

$z_{1}^{\prime}(t)=z_{2}(t)$

$z_{2}^{\prime}(t)=-\frac{1}{T} z_{2}(t)-\frac{K}{T} u(t)$,

де $K=k_{p} \cdot k_{d}-$ загальний коефіцієнт підсилення (передачі) привода.

Початкові і граничні умови для координат стану $\mathrm{z}_{1}(t)$ та $\mathrm{z}_{2}(t)$

$z_{1}(0)=\varphi_{k}, \quad z_{2}(0)=0, \quad z_{1}\left(t_{k}\right)=0, \quad z_{2}\left(t_{k}\right)=0$.

Система (4) може бути переписана у векторноматричній формі:

$\rho^{\prime}(t)=\stackrel{\mu}{A} \underline{A}(t)+\stackrel{\mu}{B} u(t)$,

де $\mathfrak{g}(t)=\left|z_{1}(t), z_{2}(t)\right|^{T}$ - вектор стану;

$\stackrel{\rho}{A}=\left|\begin{array}{cc}0 & 1 \\ 0 & -\frac{1}{T}\end{array}\right|-$ матриця стану;

$\stackrel{\rho}{B}=\left|\begin{array}{l}0 \\ -\frac{K}{T}\end{array}\right|-$ матриця входу.

Задача синтезу розв'язується лише в тому випадку, коли об'єкт задовольняє умови керованості [5, 6]. Для перевірки умови керованості об'єкта визначимо матрицю керованості $M$ : 
$\stackrel{\mu}{M}=\left|\begin{array}{ll}\mu & \mu \\ B & \stackrel{\mu}{A B}\end{array}\right|$.

Матриця $\stackrel{\sim}{M}$ виходить як розширення рядків матриці $\ddot{B}$ шляхом послідовного дописування елементів відповідних рядків матриці $\stackrel{A}{A}{ }^{\circ}$.

Користуючись матрицями $(7,8)$, одержуємо:

$$
\stackrel{\rho}{M}=\left|\begin{array}{cc}
0 & -\frac{K}{T} \\
-\frac{K}{T} & \frac{K}{T^{2}}
\end{array}\right| .
$$

Матриця $\stackrel{\mu}{M}$ квадратна, іiі визначник

$$
\operatorname{det}(\stackrel{\rho}{M})=-\frac{K^{2}}{T^{2}} \neq 0
$$

Таким чином, об'єкт керований, оскільки ранг матриці $\stackrel{\mu}{M}$ дорівнює порядку об'єкта.

Розв'язання задачі синтезу можна провести за допомогою принципу максимуму Л.С. Понтрягіна [5-8]. Якщо задача задовольняє умови нормальності [10], принцип максимуму дає не тільки необхідні, а й достатні умови оптимальності керування.

Для дослідження нормальності задачі проаналізуємо визначник $\Delta$, який складається зі стовпців матриць $\not{B}$ i $\stackrel{\mu}{A}$, що мають однакові номери. В даному випадку він збігається 3 визначником матриці $\stackrel{\sim}{M}$ :

$\Delta=\operatorname{det}(\stackrel{\rho}{M})=-\frac{K^{2}}{T^{2}} \neq 0$.

Таким чином, задача нормальна i принцип максимуму дає необхідні i достатні умови оптимальності.

Для подальшого розв'язання на основі принципу максимуму складемо гамільтоніан і канонічну систему рівнянь варіаційної задачі [5-8].

Гамільтоніан варіаційної задачі

$$
\begin{gathered}
H[\underline{\underline{\mu}}(t), \underset{\psi}{\psi}(t), u(t)]=-L[\underline{\underline{\mu}}(t), u(t)]+ \\
+\sum_{j=1}^{2} \psi_{j}(t) \cdot f_{j}[\underline{\mathrm{g}}(t), u(t)]
\end{gathered}
$$

де $f_{j}[z(t), u(t)]$ - функції, що описують праві частини диференціальних рівнянь стану (4); $\psi_{j}(t)$ - спряжені змінні, які задовольняють систему рівнянь

$\psi_{j}^{\prime}(t)=-\frac{\partial H[\underline{\xi}(t), \tilde{\psi}(t), u(t)]}{\partial z_{j}}$.

Таким чином, маємо

$$
\begin{gathered}
H[\underline{\xi}(t), \tilde{\psi}(t), u(t)]=-1+ \\
+\psi_{1}(t) \cdot z_{2}(t)-\psi_{2}(t) \cdot\left(\frac{1}{T} z_{2}(t)+\frac{K}{T} u(t)\right)
\end{gathered}
$$

Канонічна система рівнянь

$$
\begin{gathered}
z_{1}^{\prime}(t)=\frac{\partial H}{\partial \psi_{1}}=z_{2}(t) ; \\
z_{2}^{\prime}(t)=\frac{\partial H}{\partial \psi_{2}}=-\frac{1}{T} z_{2}(t)-\frac{K}{T} u(t) ; \\
\psi_{1}^{\prime}(t)=-\frac{\partial H}{\partial z_{1}}=0 ; \\
\psi_{2}^{\prime}(t)=-\frac{\partial H}{\partial z_{2}}=-\psi_{1}(t)+\frac{1}{T} \psi_{2}(t) .
\end{gathered}
$$

Задача, що розглядається, належить до класу задач iз закріпленими кінцями i нефіксованим моментом завершення керування [5]. У такій задачі для того, щоб керування $u^{*}(t)$ було оптимальним, необхідно:

1) щоб існував ненульовий вектор спряжених змінних $\rho^{*}(t)=\left[\psi_{1}^{*}(t), \psi_{2}^{*}(t)\right]^{T}$ і траєкторія стану $\rho^{*}(t)$, які задовольняють канонічну систему рівнянь (12) при $u(t)=u^{*}(t)$ і граничні умови (5);

2) у будь-який момент часу на інтервалі керування гамільтоніан $H\left[\mathrm{Z}^{*}(t), \rho^{*}(t), u(t)\right]$, що розглядається як функція незалежної змінної $u$, досягав при $u(t)=u^{*}(\mathrm{t})$ свого найбільшого значення

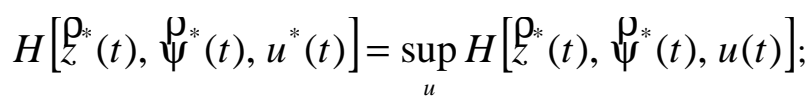

3) щоб у кінцевий момент часу $t=t_{k}$ гамільтоніан набував нульового значення

$$
H\left[\stackrel{\rho}{*}_{*}^{*}\left(t_{\mathrm{k}}\right), \stackrel{\mu}{\psi}^{*}\left(t_{\mathrm{k}}\right), u^{*}\left(t_{\mathrm{k}}\right)\right]=0
$$

Нехай $\quad$ функції $\quad{ }_{z}^{\omega}(t), \psi^{*}(t) \quad$ задовольняють канонічну систему рівнянь (12) і умови (5). Тоді, за пунктом 2 принципу максимуму, гамільтоніан досягає максимально можливого значення 


$$
H\left[\sum^{*}(t), \varphi^{*}(t), u^{*}(t)\right]=
$$$$
=\max _{u}\left[-1+\psi_{1}^{*}(t) \cdot z_{2}^{*}(t)-\right.
$$

$\left.-\psi_{2}^{*}(t) \cdot\left(\frac{1}{T} z_{2}^{*}(t)+\frac{K}{T} u(t)\right)\right]$.

Доведено, що для того, щоб керування $u^{*}(t)$ було оптимальним (гамільтоніан досягав значення (13)), необхідно, щоб його величина мала максимальне значення $|u(t)|=U_{m}$, а знак визначався знаком функції перемикання [5-7].

Для даної задачі функція перемикання має такий вигляд $[5,9,10]$ :

$\sigma\left(z_{1}, z_{2}\right)=z_{1}+T z_{2}-T K U_{m} \ln \left|1+\frac{\left|z_{2}\right|}{K U_{m}}\right| \cdot \operatorname{sgn}\left(z_{2}\right)$

де $\operatorname{sgn}(x)$ - функція знака:

$\operatorname{sgn}(x)=\left\{\begin{array}{r}1, x>0 \\ -1, x<0\end{array}\right.$

Відповідний закон оптимального керування можна подати в такому вигляді:

$$
u^{*}\left(z_{1}, z_{2}\right)=U_{\mathrm{m}} \cdot \operatorname{sgn}\left(\sigma\left(z_{1}, z_{2}\right)\right) .
$$

Функція $\operatorname{sgn}(\sigma)$ не визначена при $\sigma=0$, тому вираз (15) визначає керуючий вплив тільки для таких станів, яким відповідають на фазової площині точки, що не лежать на лінії перемикання (14).
3 точки зору технічної реалізації це несуттєво, оскільки через наявність зон нечутливості і затримки у всіх реальних перемикачів досягти суворого виконання закону оптимального керування неможливо. Практично реалізовані системи завжди виходять майже оптимальними (квазіоптимальними).

На рис. 1 приведена схема математичної моделі оптимальної за швидкодією системи керування стрілочним переводом, що функціонує відповідно до алгоритму $(14,15)$.

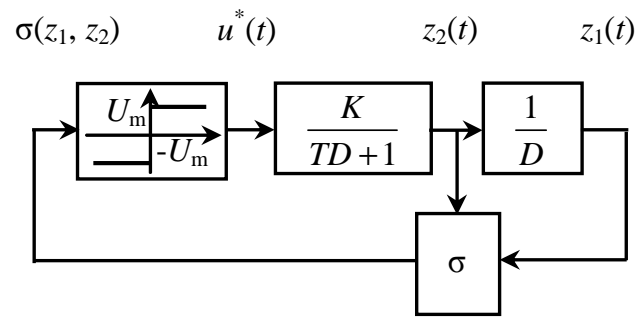

Рис. 1. Схема математичної моделі оптимальної системи керування

Дослідження системи керування, оптимальної за швидкодією. Для дослідження оптимальної системи керування була побудована Simulink-модель, яка зображена на рис. 2. Розрахунки наведені для двигуна постійного струму МСП-0,25/160 при навантаженні, що наближене до номінального, i стрілочного переводу СП-6 [1].

Початкова умова $z_{1}(0)=280^{\circ}=4,887$ рад встановлюється в інтеграторі. Результати моделювання подані на рис. 3-5.

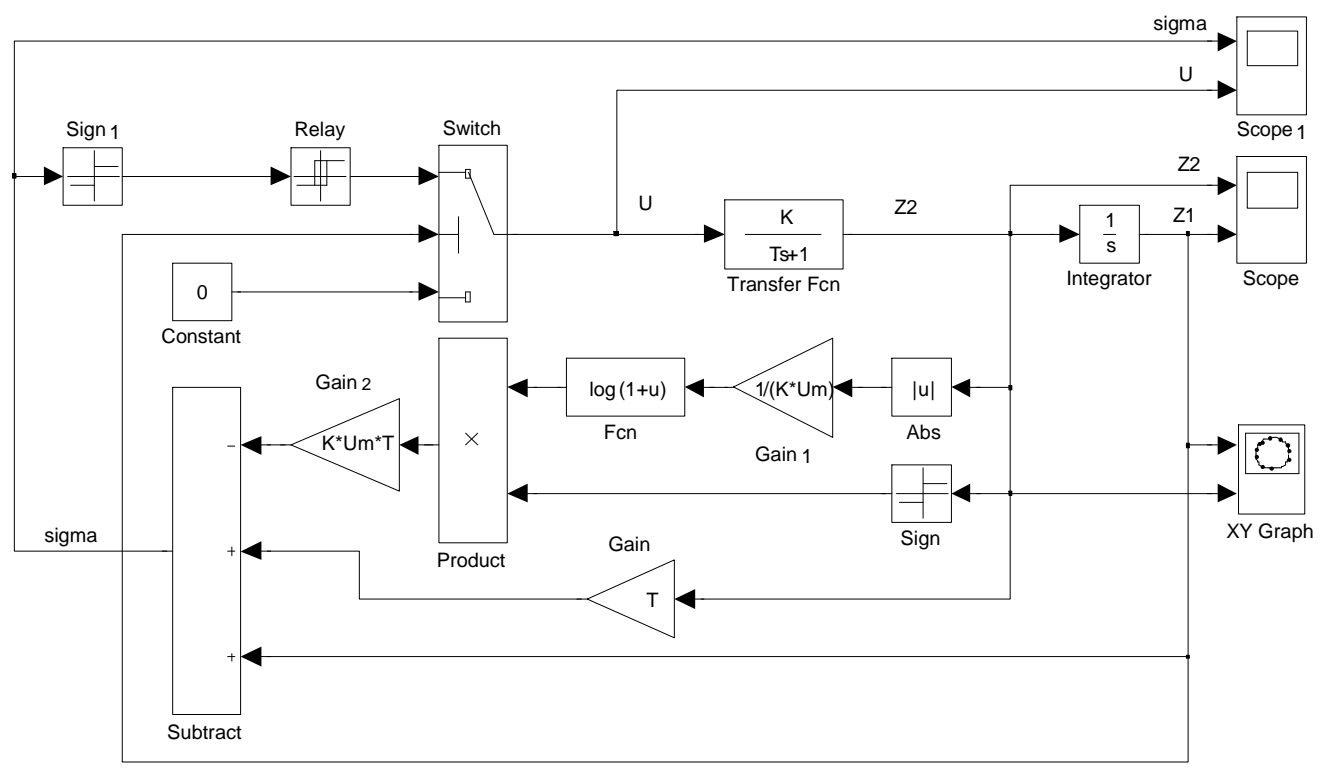

Рис. 2. Simulink-модель оптимальної за швидкодією системи керування 
На рис. 3 наведена залежність функції перемикання б від часу. 3 рис. 4 видно, що оптимальне за швидкодією керування здійснюється шляхом встановлення максимального значення напруги живлення на початковій ділянці переводу стрілки й одноразової зміни ऑiі знака на кінцевій ділянці керування.

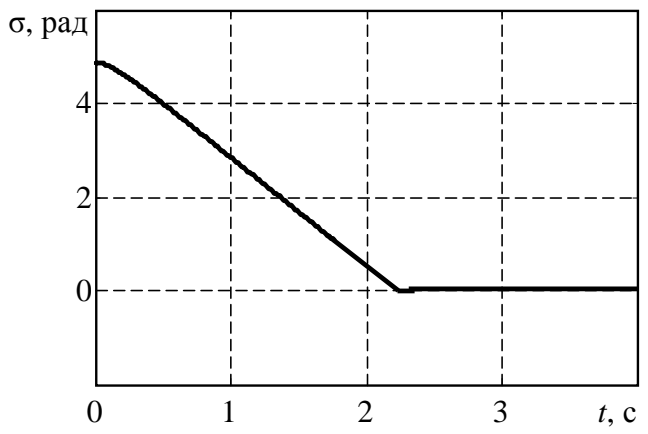

Рис. 3. Залежність функції перемикання б від часу

Це призводить до швидкого розгону головного вала й обертання його 3 максимальною швидкістю на початковій ділянці роботи, який триває до моменту часу $t_{1}=2,23 \mathrm{c}$.

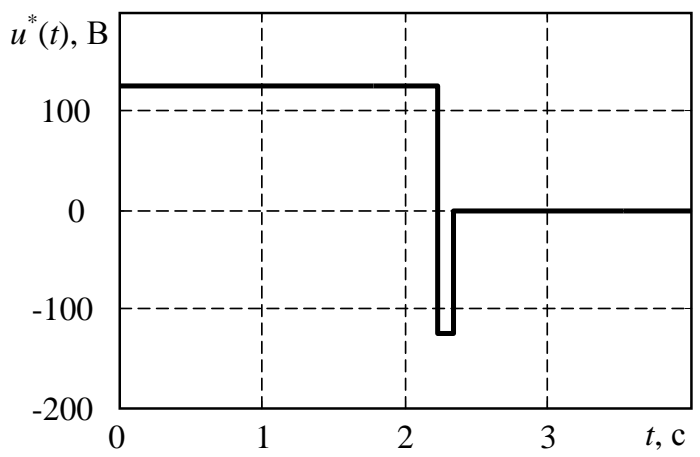

Рис. 4. Залежність напруги живлення $u^{*}(t)$ від часу при керуванні, що є оптимальним за швидкодією

На кінцевому етапі від моменту часу $t_{l}$ до моменту закінчення керування $t_{k}$ внаслідок зміни знака напруги живлення здійснюється енергійний реверс двигуна, i тому вихідний вал за мінімальний час $\Delta t=t_{k}$ $t_{1}=0,12$ с гальмується до нульової швидкості в момент замикання $t_{k}$, після чого напруга живлення вимикається.

Загальний час оптимального за швидкодією керування становить 2,35 с.

Початок реверса відповідає недоходу головного вала до замикання $6,7^{\circ}$ або недоходу шибера 3,67 мм. Звернемо увагу, що в стрілочному переводі СП-6 замикання автоперемикача має місце при недоході менше 4 мм.

Відзначимо, що при моделюванні абсолютне значення максимальної напруги, що прикладається до двигуна (рис. 4), менше номінального 160 В. Різниця напруг відповідає напрузі зрушення двигуна при навантаженні, близькому до номінального. Цим враховано вплив на роботу привода моменту сил опору навантаження.

На рис. 5 зображена фазова траєкторія системи керування стрілочним переводом при оптимальному за швидкодією керуванні.

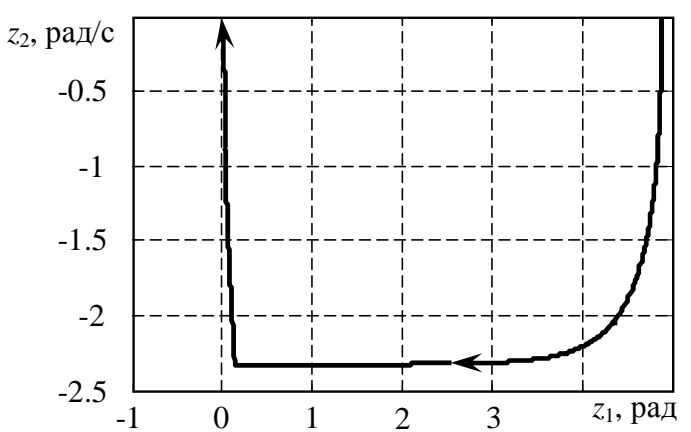

Рис. 5. Фазова траєкторія системи при керуванні, що є оптимальним за швидкодією

Аналіз проблеми практичної реалізації оптимальної за швидкодісю системи керування. Можлива функціональна структура системи керування стрілочним електроприводом наведена на рис. 6.

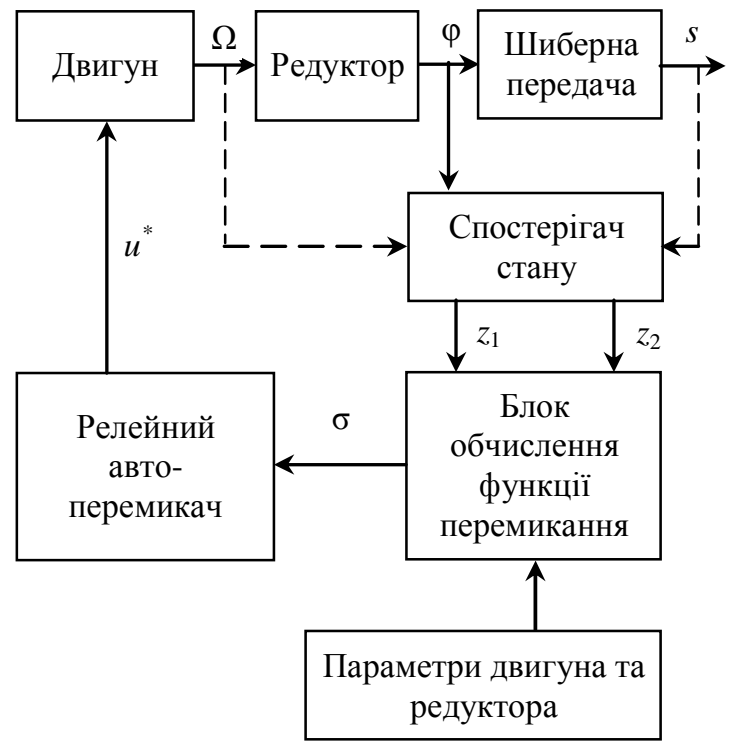

Рис. 6. Функціональна структура системи керування стрілочним електроприводом, що $є$ оптимальною за швидкодією 
І Н Ф О Р М А Ц Й Н О - КЕ Р У Ю Ч І С И С Т Е МИ Н А З А Л І З Н И Ч Н О М У Т Р А Н С П О Р Т І

Блок спостерігача стану визначає кут повороту головного вала $\varphi$ і кутову швидкість його обертання $\varphi^{\prime}$, перераховує їх в змінні $\mathrm{z}_{1}, \mathrm{z}_{2}$ за формулами (3). Вимірювання величин $\varphi$ і $\varphi^{\prime}$ може бути виконано шляхом установлення на головний вал додаткових елементів - датчиків кута і кутової швидкості обертання. В даний час такі пристрої можуть бути реалізовані на базі цифрових датчиків. Замість датчика кута повороту можливе використання датчика лінійного переміщення шибера $(s)$.

Блок обчислення функції перемикання $\sigma\left(z_{1}, z_{2}\right)$ може бути реалізований на базі мікроконтролера 3 програмою обчислень відповідно до рівняння (14).

Реле автоперемикача здійснює керування шляхом комутації полярності напруги живлення електродвигуна в момент зміни знака функції перемикання $\sigma$.

Таким чином, існує принципова можливість практичної реалізації закону оптимального керування $(14,15)$.

Основною проблемою практичної реалізації такого керування $є$ необхідність точного розрахунку моменту перемикання і його залежність від поточних параметрів привода. Помилка в розрахунку може привести до недоходу шибера до кінцевої точки i невиконання операції замикання стрілки.

Крім того, при реверсивному гальмуванні виникають значні комутаційні струми, що призводить до перенавантажень елементів кола живлення.

3 точки зору практичної реалізації на базі існуючих стрілочних переводів виникнуть суттєві труднощі в реалізації оптимального за швидкодією керування внаслідок неминучості зміни схеми керування приводом. Можливий варіант схемного розв' язання задачі - розпаралелювання кіл контролю стрілки і робочого кола керування електродвигуном, що досить часто зустрічається в сучасних системах керування.

Слід також зазначити, що при наявності запізнення i неточності формування закону оптимального за швидкодією керування в системі може виникнути змінний режим автоколивань, що призводить до багаторазової комутації напруги живлення і затягування процесу переводу.

\section{Висновки}

1. Для зменшення впливу конструктивних особливостей стрілочних переводів на середній термін ï служби запропоновано знизити взаємовплив вістряка і рамної рейки в кінці переводу вістряка.

2. Для завершення робочого ходу шибера 3 нульовою кінцевою швидкістю запропоновано застосувати систему керування стрілочним переводом, оптимальну за критерієм максимальної швидкодії.

3. Складено схему математичної моделі оптимальної за швидкодією системи керування стрілочним переводом, на основі якої побудовано i досліджено Simulink-модель стрілочного переводу СП63 двигуном постійного струму МСП-0,25/160.

4. Запропоновано функціональну структуру системи керування стрілочним електроприводом, що $є$ оптимальною за швидкодією, коротко позначено можливі шляхи іiї технічної реалізації.

5. Основні проблеми практичної реалізації оптимального за швидкодією керування стрілочним електроприводом - необхідність точного розрахунку моменту перемикання знака напруги, значні комутаційні струми та при наявності запізнення i неточності формування закону оптимального за швидкодією керування змінний режим автоколивань.

6. Слід вважати часові характеристики системи керування стрілочним електроприводом, яка $\epsilon$ оптимальною за швидкодією, потенційно досяжними, що дозволяє, з одного боку, замовнику обгрунтувати реалістичні вимоги до швидкодії перспективних систем, a, 3 іншого - розробнику бачити гранично досяжні за швидкодією характеристики.

7. Доцільно побудувати системи керування стрілочним електроприводом, що є оптимальними за іншими критеріями (наприклад, за критерієм мінімуму квадратичного показника якості), але простішими 3 точки зору практичної реалізації, та порівняти їх часові характеристики з потенційно досяжними.

\section{Список використаних джерел}

1. Сапожников Вл. В., Елкин Б. Н., Кокурин И. М., Кондратенко Л. Ф., Кононов В. А. Станционные системы автоматики и телемеханики / под ред. Вл. В. Сапожникова. Москва : Транспорт, 1997. $432 \mathrm{c.}$

2. Каменев А. И., Минков Е. Ю., Шуваев В. В., Савицкий А.Г. Анализ режима работы быстродействующих стрелочных приводов. Автоматика, связь, інформатика. 2003.№ 12. C. 2-5.

3. Рибкін В. В., Баль О. М., Бондаренко I. О. Аналіз експлуатаційної стійкості елементів стрілочних переводів Вестник Днепропетровского национального университета железнодорожного транспорта. 2011. № 38. С. 127-133.

4. Парфенов В. И., Разгонов В. П., Ковригин М. А. Анализ дефектов и возможности диагностики стрелочных переводов. Вестник Днепропетровского начионального университета железнодорожного транспорта. 2007. № 15. С. 16-18.

5. Понтрягин Л. С., Болтянский Гамкрелидзе Р. В., Математическая теория оптимальных процессов. Москва : Наука, 1969. 384 с.

6. Boscain U., Piccoli B. Optimal synthesis for control 
systems on 2-D manifolds. Springer-Verlag, 2004. $262 \mathrm{p}$.

7. Hull, D. Optimal control theory for Applications. Springer-Verlag, 2003, 384 p.

8. Zhou Z., Doyle J., Glover K. Robust and Optimal control. Prentice Hall, 1996. 616 p.

9. Piccoli B., Sussmann H. J. Regular synthesis and sufficiency conditions for optimality. Control and optimization. 2000. Vol. 39. No. 2. P. 359-410.

10. Sussmann, H. J. Regular synthesis for time-optimal control of single-input systems in the plane. Control and optimization. 1987. Vol. 25. P. 1145-1162.

Нейчев О. В., Садовый К. В., Сосунов А. А., Хисматуллин В. Ш. Синтез оптимальной по быстродействию системы управления стрелочным электроприводом.

Аннотация. В статье предложен синтез системы управления стрелочным электродвигателем с нулевой скоростью в конце перевода, оптимальной по критерию максимального быстродействия. Приведены математическая формулировка цели управления, критерия оптимальности и ограничение на управляющее воздействие. Разработана математическая модель привода с двигателем постоянного тока. Проведен анализ управляемости объекта и нормальности вариационной задачи. Синтез оптимальной системы управления выполнен с использованием принципа максимума Л. С. Понтрягина.

Ключевые слова: стрелочный электропривод, остряк, рамный рельс, оптимальная по быстродействию система управления, принцип максимума.

Nejchev O., Sadovyi K., Sosunov A., Khismatulin V. The speed-optimal control system synthesis of switch electric drive.

Abstract. The algorithm of operation of switch electric drives (the electric motor together with a reducer and a safety friction clutch) in railway transport is constructed in such a way that at the moment of completion of the working stroke of the tongue, its linear speed has the maximum value, and the braking process is provided only by the mechanical counteraction of the frame rail on the moving tongue. This process is accompanied by increased wear of the contacting parts, the deformation of the tongue, the rods and the elements of the hinged joints. To reduce the intensity of mechanical wear on the parts of the electric drive and the switch it is necessary to reduce the kinetic energy of the moving masses by reducing the velocity at the time the transfer is completed to zero or to a sufficiently small value. On the other hand, from the time of switching tongue depends the time of setting the routes, processing capacity of stations, sorting hills, that is, the efficiency of the transport complex as a whole. The aim of the article is to synthesize the control system of an switch electric motor with zero speed at the end of the translation, optimal by the criterion of maximum speed. The mathematical formulation of the goal of management, the criterion of optimality and the constraints on the control action are presented. A mathematical model of a drive with a DC motor is developed. The controllability of the object and the normality of the variational problem are analyzed. Synthesis of the optimal control system is performed using the maximum principle of L.S. Pontryagin. The analysis of the problem of practical implementation of the speed-optimal control system is briefly analyzed.

Keywords: switch electric drive, tongue, frame rail, speedoptimal control system, maximum principle.

Надійшла 03.10.2019 p.

Нейчев Олег Володимирович, к.т.н., дочент кафедри «Автоматика та комп'ютерне телекерування рухом поїздів» Українського державного університету залізничного транспорту, Харків, Україна. E-mail: khnow_1963@ukr.net ORCID ID: https://orcid.org/00000002-9093-0804

Садовий Костянтин Віталійович, к.т.н.,, доцент кафедри Харківського національного університету Повітряних Cuл. E-mail: 971sadovyi@gmail.com, ORCID ID: https://orcid.org/0000-0003-2703-9696

Сосунов Олександр Олексійович, к.т.н., доцент кафедри «Автоматика та комп'ютерне телекерування рухом поїздів» Украӥнського державного університету залізничного транспорту. E-mail: sosunov63@kart.edu.ua ORCID ID: https://orcid.org/0000-0003-2175-7363

Хісматулін Володимир Шайдулович, к.т.н., проф. кафедри «Автоматика та комп'ютерне телекерування рухом поӥздів» Украӥнського державного університету залізничного трансnорту. E-mail: khisvs@kart.edu.ua ORCID ID: https://orcid.org/0000-0001-7578-1217

NejchevOleh Vladimirovich, candidate of technical sciences, associate professor of department of "Automat and computer telecontrol by motion of trains" of the Ukrainian state university of railway transport, Kharkiv, Ukraine. Email: $\quad$ khnow_1963@ukr.net ORCID ID: https://orcid.org/0000-0002-9093-0804

Sadovyi Kostiantyn Vitalyevich, candidate of technical sciences, associate professor of department of the Kharkiv national university of Air Force, Kharkiv, Ukraine. E-mail: 971sadovyi@gmail.com ORCID ID: https://orcid.org/00000003-2703-9696

Sosunov Aleksandr Alekseevich, candidate of technical sciences, associate professor of department of "Automat and computer telecontrol by motion of trains" of the Ukrainian state university of railway transport, Kharkiv, Ukraine. Email: $\quad$ sosunov63@kart.edu.ua ORCID ID: https://orcid.org/0000-0003-2175-7363

Khismatulin Vladimir Shaydullovich, candidate of technical sciences, professor of department of "Automat and computer telecontrol by motion of trains" of the Ukrainian state university of railway transport, Kharkiv, Ukraine. E-mail: khisvs@kart.edu.ua ORCID ID: https://orcid.org/ 0000$\underline{0001-7578-1217}$ 